\title{
O DESENVOLVIMENTO DO POTENCIAL DE INTEGRAÇÃO GUARANI NA SEGUNDA METADE DO SÉCULO XVIII ${ }^{1}$
}

Maria Cristina dos Santos*

\section{Uma palavra sobre "política indigenista"}

Durante muito tempo e inclusive na atualidade, os países com população indígena propõem a inserção desta na sociedade global, segundo as necessidades econômicas e sobretudo políticas e ideológicas dos respectivos Estados Nacionais. Temas como territórios e legislação indígena, teoricamente presentes nas "políticas indigenistas" refletem, na verdade, as necessidades dos governos de refazer ou reafirmar uma ideologização arbitrária da cultura indígena, resgatando dela os aspectos convenientes ao sistema político nacional. O processo de ideologização exógeno da cultura parece ser comprovado pela busca interna de reafirmação de identidade étnica; que apresentará variações conforme os tipos e intensidades de contato entre os indígenas e a sociedade global.

Entre os Estados americanos atuais se observa diferentes graus de integração e de importancia dos grupos indígenas para o "todo nacional". Até a década de 80 no Brasil, Eunice Durham afirma que o problema ainda reside em definir um lugar para o índio na sociedade nacional. Desde a época da colonização o problema tem alimentado, segundo a

- Professora do Departamento de História da PUCRS.

1 Comunicação apresentada no Encontro de História e Geografia do Prata. Instituto Histórico e Geográfico do Rio Grande do Sul. Porto Alegre, Agosto, 1994.

Estudos Ibero-Americanos. PUCRS, v.XXI, n.2, p. 155-171, dezembro, 1995 
autora, aquecidos debates que permitiram, a nível puramente ideológico, enfrentamentos radicais. A imagem do índio foi exaltada ou denegrida, servindo simultaneamente como metáfora de liberdade natural e como protótipo do atraso a ser superado no processo civlizatório de construção da nação. $\mathrm{Na}$ atualidade se pode constatar uma realidade um tanto inercial:

"os defensores dos índios têm vencido brilhantemente a batalha ideológica e seus inimigos têm vencido a guerra real que se trava na sociedade brasileira contra os grupos indígenas, (...). É tempo de transferir a luta do campo puramente ideológico para tentar alcançar alguma eficácia política. Precisamos, portanto definir o campo político no qual pode-se inserir a questão indígena. ${ }^{2}$

O campo político da questão indígena relaciona-se portanto intimamente com o processo de construção da nação, que a posteriori fundamentará as ideologias nacionalistas dos Estados.

Assim, o indigenismo enquanto categoria histórica de análise foi apresentado por Nolasco Armas vinculado à ideologia de estruturação da nação mexicana. No México pós-revolucionário a necessidade de adequação da nova nação com sua realidade social fez com que o indigenismo se articulasse com o pensamento oficial, convertendo o indígena num elemento e problema da recém inaugurada "ação antropológica". ${ }^{3} \mathrm{O}$ reforço das idéias indigenistas e o desenvolvimento dos conceitos antropológicos fazem parte da estruturação homogeneizadora da própria nação mexicana: "o indigenismo é mexicano, feito no México e para os mexicanos usarem". ${ }^{4}$ Esse ideal indigenista, estreitamente vinculado à ideologia pós-revolucionária do Estado mexicano, se difunde por toda América Latina a partir dos anos 40, como um reforço necessário de ampliação do ideal populista.

No Brasil a partir do início do século XX, o indigenismo foi desenvolvido e usado pelos atores do campo político, consistindo em idéias e práticas específicas de agências que se utilizavam do eufemismo

2 DURHAM, Eunice R. "O lugar do índio". Novos Edudos CEBRAP. São Paulo: Brasileira de Ciências, v. 1(14:45-49). Nov. 1982:45.

3 SOUZA LIMA. Antonio C. "On indigenism and nationality in Brazil." In: GREG, U. SCHERZER, J. (Edit.). National States and Indian in Latino American. University os Texas Press. 1991:237.

4 NOLASCO ARMAS. Margarita. "A antropologia aplicada no México e seu destino final: o indigenismo" . In: JUNQUEIRA, C. CARVALHO, A. (Edit.). Antropologia e indigenismo. (67-85). São Paulo: Cortez, 1981:72. 
da "proteção fraternal". Nos objetivos selecionados por Souza Lima, se pode notar que tipo de "proteção" pretendiam essas agências e, sobretudo os níveis de integração que a "ação política indigenista" se propõe alcançar com a população indígena:

- Convivência pacífica com a população indígena;

- Integração dos indígenas com a população rural;

- Fazer com que os indígenas adquiram maneiras civilizadas;

- Efetivar o povoamento do interior;

- Ter acesso aos recursos econômicos dos territórios indígenas;

- Aumentar a produtividade agricola dos indígenas;

- Utilizar os indígenas como trabalhadores;

- Reforçar o nacionalismo.

Conforme Antonio Iasi na década de 70 no Brasil, quando se fala em integração através da "política indigenista oficial" se pensa em:

um modelo operacional - mentalidade e práxis - segundo o qual o índio é considerado um ser incapaz - um menor, um tutelado - com uma existência provisória - com vistas à sua total e indiscutível absorção pela sociedade nacional - supostamente mais humana -, mediante pressōes - projetos e planejamentos sócio-econômicos e um sistema educativo alienado - dissociado da cultura indígena e alienante - orientado para mudanças sociais, econômicas e políticas. $^{6}$

Entretanto, no Paraguai durante os anos 60, vigorava um certo orgulho da "praxis integracionista" estatal que havia conseguido formar com os indígenas a "Banda de Músicos do Territorio Militar do Chaco". Segundo o Autor, cerca de $70 \%$ dos componentes são descendentes diretos dos Guarani Sub-Andinos, e se encontram

"definitivamente integrados como ciudadanos paraguayos a la comunidad nacional. ...si bien el medio ambiente ha contribuido en medida importante para que fuera posible ofrecer a los guaraníes de Mariscal Estigarribia una continuidad en el proceso de integración, estos también han demostrado aptitudes para una constante y por tanto initerrumpida superación. ...Debemos recalcar el hecho de que en una segunda generación, han desparecido los vestigios culturales

5 SOUZA LIMA 1991:249 e ss.

6 IASI, Antonio. "Integração ou Extinção". Revista de Cultura Vozes. Petrópolis. Ano 70, v. LXX, (3:15-22) 1976:15. 
autóctonos, que podrían haber tenido aún los contigentes originales ...Podemos hablar de paraguayos oriundos de Mariscal Estigarribia. Esto ha sido posible porque, ha imperado la necesaria capacidad para conducir inteligentemente el proceso de aculturación. ...Alfabetizados, se les abre al joven la puerta de los cuarteles. Sale con documentación hecho un perfecto ciudadano y entra libre de perjuicios raciales indiscriminado a compartir con las inquietudes propias de toda colectividad paraguaya."

Os indígenas, por seu lado, ao assinarem a Declaración de Barbados II, entendem que o sistema educativo formal e os meios de comunicação de massa compõem os meios utilizados pela sociedade global para concretizar a dominação cultural, junto com "la política indigenista en la que se incluyen procesos de integración o aculturación a través de diversas instituciones nacionales o internacionales, misiones religiosas, etc. ${ }^{8}$

O potencial de integração representa segundo Cardoso de Oliveira, "aquelas características do sistema interétnico que, presentes na situação de contato, poderão ser tomadas como aqueles elementos responsáveis pela integração". O potencial de integração pode ser avaliado na proporção em que os elementos possam ser traduzidos em mecanismos psicosociais em operação no momento do contato. Desta forma pode-se averiguar como se efetiva, se é que, a integração do indígena na sociedade global.

7 BORGOGNON, Juan Alionso. "Aborigenes Guaraníes del Chaco Paraguayo". Suplemento Antropológico. Asunción, v. 1, (2:263-283), 1966:272-273. O destaque no texdo é meu.

8 Declaración de Balbados II, 28 de junio de 1977. En: CONTRERAS, Jesús. (Comp.). Identidad étnica y movimientos indios. Madrid: Editorial Revolución, 1988:178.

Cfe. CARDOSO DE OLIVEIRA, Roberto. A sociologia do Brasil indígena. Rio de Janeiro: Tempo Brasileiro, 1978:87. A consecução da "aliança hispano-guaraní" num primeiro momento, e depois com o avanço das frentes coloniais sobre o território indígena, a "solicitação" para incorporação ao sistema de reduções, demonstram uma acessibilidade e condescendência do Guarani que podem ser tomadas como elementos responsáveis pela integração. Posteriormente, durante o período das Reduções a manutenção do idioma indígena, a adaptação a uma economia de caráter sedentário e uma distribuição sócio-espacial dentro do povoado que guardava algumas referências com os elementos tradicionais; assim como a condescendência dos jesuítas com a organização das casas coletivas ou a interminável paciência com o costume da poligamia; são exemplos de como se pode avaliar o desenvolvimento do potencial de integração até o momento da expulsão dos jesuítas. 
Conforme Laraia, ainda que sejam tomados como sinônimos, a integração supõe a participação econômica e social do grupo tribal na sociedade ocidental, com a adoção inclusive de diversos costumes e práticas tecnológicas, sem que isso implique a perda de identidade étnica. Já a assimilação implica uma perda quase total das particularidades culturais e da identidade étnica no seio da sociedade envolvente. ${ }^{10}$

Como se pode perceber, há que considerar a complexidade - para não dizer ambigüidade - inerente ao conceito de integração. Ou seja, há que comprendê-la conforme a realidade a que se refere e com que propósitos está sendo utilizada, pois tanto os Estados Nacionais (ou a administração colonial em seu momento), como os distintos grupos étnicos o utilizam em seus discursos. ${ }^{11}$

\section{Modelo de Integração Borbônica}

Na segunda metade do século XVIII, a partir da expulsão dos jesuítas, uma sociedade Guarani-Missioneira se encontra frente a uma nova situação de contato. Desnecessário ressaltar que as características deste novo sistema interétnico, já são completamente diferentes dos primeiros contatos. Se pode dizer que nesta nova situação se verifica um complexo pluriétnico: por um lado uma sociedade colonial criolla e, por

10 BARROS LARAIA, Roque de. "Integração e utopia". Revista de Cultura Vozes. Petrópolis. Ano70, (3:5-13), 1976:13.

11 Especificamente entre os Guarani, o tema da integração foi trabalhado numa primeira abordagem por CADOGAN, Léon. "En torno al problema indigenista en el Paraguay". Boletín Indigenista. México. XVII, marzo 1958:28-31. Posteriormente já com interesses ideológicos claramente definidos aparecem os estudos de BEJARANO, Ramón César. "El problema indígena en el Paraguay y su posible solución". Suplemento Antropológico. Asunción, v. 1 (1:39-48), 1965; BARTOLOMÉ, Miguel A. "La situación de los Guaraníes (Mbyá) de Misiones (Argentina)". Suplemento Antropológico. Asunción, v. 2 (2:164-184); CHASE-SARDI, Miguel. "La situación actual de los indígenas del Paraguay". Suplemento Antropológico. Asunción, v. 6, (1-2:999), 1976; e do mesmo autor "Las políticas indigenistas en el Paraguay". Suplemento Antropológico. Asunción, v. XXI, (1:265-271), 1987. Ainda que estes últimos mencionem importantes dados sobre as demandas indígenas para a integração, o estudo de Bartomeu MELIÀ e George e Friedl GRÜNBERG, desenvolvido dentro do Projeto Paï Tavyterã é um dos exemplos mais evidentes de como esses indígenas pensam e encaminham seu projeto de integração. "Etnografía guaraní del Paraguay contemporáneo: Los Paï Tavyterā". Suplemento Antropológico. Asunción, v. 11, (1-2:151-295), 1976. 
outro, vários grupos indígenas, entre os quais estão os Guarani, que trazem incorporado às adaptações de seus princípios culturais as mudanças pela convivência com o elemento europeu. Os aspectos que no primeiro momento foram tomados como propícios à integração se revelarão, durante o período Bourbônico, como tácitos impedimentos à imediata integração do Guarani na sociedade colonial. Os elementos que ativarão o desenvolvimento do potencial de integração nesta nova situação de contato, estarão refletidos nas propostas ou Projetos de Governo que os Guarani recebem desde a administração metropolitana ou colonial e na atitude dos indígenas como partícipes deste momento de alteração da ordem vigente. Estes Projetos ou Planos de Governo popõem textualmente a integração, mas, tal como a "política indigenista" do século XX, aplicam os princípios da assimilação.

$\mathrm{O}$ projeto reformista como um todo impunha a necessidade de (re)conhecer melhor o continente americano, seus povoados, sua gente, seus recursos, recuperando os lugares dominados ou ameaçados por estrangeiros, eliminando a oposição do poder local, para alcançar objetivos tais como: agilizar as transações mercantis entre colônias e metrópole, organizando a economia das primeiras como satélite da segunda; reduzir a autonomia de gestão e controle econômico locais, diminuindo as relações inter-regionais e fazendo com que cada região se voltasse diretamente para a Península.'

A princípios do século XVIII, os territórios que compunham o governo do Rio da Prata, juntamente com Córdoba de Tucumán, Paraguay e Alto Perú, formavam parte do que Assadourian definiu como "espaço peruano", pois as economias de todas estas regiōes haviam organizado sua produção em função das minas de prata de Potosí. ${ }^{13}$ Além disso, politicamente todos estes territórios estavam integrados e dependentes do Vice-Reinado do Perú.

A criação do Vice-Reinado do Rio da Prata em 1776, proporcionará à região um quadro institucional próprio. Tanto os espanhóis, como os criollos, quanto os indígenas que aí se encontravam, passarão, pelo menos no que no aspecto administrativo se refere, de uma situação de província marginalizada do Vice-Reinado do Perú a um núcleo que mantém relações diretas com a metrópole, com tudo que isto significa:

12 Cfe. PEREZ HERRERO, Pedro. Comercio y mercados en América Latina Colonial. Fundación Mapfre América. MAPFRE S.A. Madrid. 1991:229.

13 Cfe. ASSADOURIAN, Carlos Semprat. El sistema de la economia colonial. Mercado interno, regiones y espacio económico. Lima: Instituto de Estudios Peruanos, 1982. 
receber ordens diretas, prestar conta, e administrar sua relativa autonomia de decisões. ${ }^{14}$

Considerando estes aspectos se pode concordar com J. Lynch quando assinala que, para o restante do Império Espanhol, a política reformista de Carlos III supôs um ressurgimento econômico e político; para o Rio da Prata, significou uma nova existência; e no que se refere à situação dos índios de Paraguai e Uruguai, converteram-se numa preocupação constante para as autoridades centrais de Madrid e para o governo do Vice-Reinado de Buenos Aires. As "provincias de abajo" conformavam uma região que apresentava todas as necessidades para aplicar a nova política reformista. Segundo Lynch, em poucas regiões isso seria tão verdadeiro quanto no Rio da Prata, ${ }^{15}$ ao que se acrescentaria a incorporação das comunidades ex-jesuíticas de índios Guarani.

O período compreendido entre $1768-1776$ é talvez um hiato político-administrativo - um a mais no caso do Paraguai - no qual, o que existia antes já não vale e tampouco está muito claro o que vigora a partir de então. Por isso, as primeiras tentativas de mudanças administrativas acontecem mais dentro de uma perspectiva continuista da política anterior, com exceção da constante preocupação de apagar tudo o que havia de jesuítico, como se assim demonstrassem ser mais regalistas que o próprio Rei.

Os Guarani de Missões, herdeiros de um dirigido isolamento das redusões em relação à Província do Paraguai, se encontrarão de repente imersos numa maré de propostas e projetos para integrá-los, sobretudo economicamente, na sociedade colonial das províncias do Rio da Prata. No distrito que se converteu em Vice-Reinado do Rio da Prata, a população indígena se compunha dos que viviam livremente junto aos espanhóis, dos sujeitos à encomienda e dos índios missioneiros. Claro está que a vida da maior parte destes indígenas não se diferenciava da vida dos demais encomendados do restante do Império.

O complexo dos Trinta Povos de Missões passa assim, por uma seqüência de mudanças exógenas e endógenas. Ou seja, sua administração e prioridades internas mudam e a sociedade na qual devem integrarse também passa por uma alteração política e econômica. O Guarani

14 Archivo General de Indias, Sec. Buenos Aires, Leg. 354. Real Cédula con Instrucción de Gobierno al Virrey Pedro Cevallos, para el mando político y económico de las provincias del Río de la Plata. San Ildefonso, 15 de agosto de 1776.

15 LYNCH, John. Administración colonial española (1782-1810). El sistema de Intedencias en el Virreinato del Río de la Plata. Buenos Aires. Universitária, 1962:28 
colonial se distribui em espaços de importância econômica e ideológica fundamental para a aplicação das reformas bourbônicas que buscam a homgeneidade administrativa e crescimento econômico global da colônia.

Os Planos de Governo e as mudanças propostas até 1770 afetam de forma mais específica o complexo população/produção dos Povoados Missioneiros.

Francisco Bucareli y Ursúa, nomeado Tenente Governador das Províncias do Rio da Prata, recebeu o encargo de cumprir com o Real Decreto de 21 de fevereiro de 1767, que determinava a expulsão dos jesuítas. Um encargo que se multiplicava nas diferentes frentes onde atuavam os membros da Companhia de Jesus: colégios, seminários, residências e a direção dos Trinta Povos, além das atividades econômicas que desenvolveram na Província. Para ocupar o vazio político-administrativo e o trabalho espiritual dos jesuítas com os Guarani, Bucareli elaborou $^{16}$ a primeira Instrução ${ }^{17}$ normativa para os Administradores Gerais. Bucareli estabeleceu dois objetivos primordiais a serem alcançados com a aplicação do novo Plano de Governo:

1 - radicar a estos Indios un verdadero conocimiento de los adorables Misterios de Nuestra Santa Fee. (...)

2 - proporcionar à estos Indios aquellos beneficios y conveniencias temporales que se adquieren por los medios de la civilidad, de la cultura, y del comercio. ${ }^{18}$

Tais objetivos já aparecem nas Leyes de Indias e foram reforçados na Recompilação e em várias oportunidades nas quais foi necessário dar clareza à missão dos espanhóis na América. Se é certo que a Instrução

16 Conforme a análise comparativa de Ernesto Maeder, Bucareli utilizou o Diretório ditado a 2/5/1757 pelo Governador Mendonça Furtado para as Missões Jesuíticas do Grão-Pará e Maranhão, como modelo às normas agora realizadas para as Missōes Guarani. Cfe. MAEDER, E. "El modelo portugués y las Instrucciones de Bucareli para las misiones de Guaraníes". Estudos Ibero-americanos, v. XIII (2:135-149). Porto Alegre: PUCRS, 1987.

17 AHNM. Sec. Consejos de Indias, Leg. 21371. "Instrucción que formó el Theniente Gral. Dn. Franc ${ }^{\circ}$. Bucareli y Ursúa, Governador de Buenos Aires para arreglo de los Governadors nombrados para los Pueblos de Indios Guaraníes del Paraguay y Paraná. Firmada en Candelária, 23 de agosto de 1768." Também há uma cópia publicada en BRABO, Francisco Javier. Colección de documentos relativos a la expulsión de los jesuitas de la Repúbluca Argentina y del Paraguay en el Reinado de Carlos III. Establecimiento Tipográfico de José María Pérez, Madrid. 1872: 199-222.

18 AHNM. Sec. Consejos de Indias, Leg. 21371. "Instrucción ...1768". fol. 1R. 
foi uma tradução do modelo português, tal como concluiu Maeder, a legislação indiana aparece não só como a necessária legitimidade jurídica senão também como substrato ideológico do documento.

Além destes objetivos, Bucareli chama atenção para as mudanças que devem ser encaminhadas no que diz respeito ao idioma, à forma de vestir, à distribuição espacial das casas comunitárias e, com especial atenção, à hierarquia que deve ser observada dentro dos povoados.

As propostas de mudanças sociais e administrativas introduzidas por Bucareli representam, assim, uma síntese das dificuldades acumuladas durante os séculos anteriores e uma antecipação dos problemas que a população Guarani-missioneira representará para a nova administração. As referências de Bucareli ao período anterior, desacreditam de tal forma o trabalho dos jesuítas que cabe perguntar se tamanha descaracterização não estaria relacionada ao absoluto desconhecimento, ou de Bucareli sobre a realidade que pretende transformar, ou ao nosso próprio sobre o funcionamento das Missões. Sobre o primeiro, é bem verdade que o Governador elaborou a Instrução apremiado pelo tempo e pelas circunstâncias, e não se tem informação de que tenha realizado alguma visita aos Povoados, pelo menos até 1770, para tomar consciência do estado em que se encontravam. Mas também é certo, que até a Expulsão, as notícias sobre o esplendor e progresso das Missões chegaram até nós quase exclusivamente da mão dos jesuítas. Sem desprezar os estudos desenvolvidos sobre o fenômeno "Missões Jesuítico-Guaranis", não posso evitar a constatação imediata que, apesar dos equívocos cometidos por Bucareli, não se podia esperar milagres civilizatórios com o Guarani que recebeu para administrar. A recuperação do trauma da perda do pai-padre, se refletirá na conversão do potencial de integração do Guarani-jesuítico (das reduções) em Guarani-colonial (de povoados, cidades e conchavos).

A divisão administrativa entre dois Governadores Gerais para os 30 Povos, proposta por Bucareli, durou pouco mais de um ano, quando Juan Francisco de la Riva Herrera, responsável pelo governo dos vinte povos do Uruguay e Paraná, ${ }^{19}$ pediu afastamento do cargo, por considerar-se "inepto para ello", além de não contar com "subalternos idóneos". ${ }^{20}$

19 Uruguay: San Javier, San Jose, Concepción, Mártires, San Carlos, Apóstoles, Santa Maria La Mayor; Paraná: Candelária, Loreto, Corpus, Santiago, San Ignacio Guazú, San Ignacio Mini, San Cosme, Trinidad, Santa Maria de la Fe, Jesús, Santa Ana, Santa Rosa e Itapúa. Cfe. BRABO. 1872: 218-222.

20 AGN. Sala IX-Colonia, leg. 18-6-2. Solicitud de Riva Herrera a Bucareli. Candelaria, 8 de septiembre de 1769 . 
Ao deixar o cargo, Riva Herrera elaborou um detalhado relatório como o próprio título indica: "Practica de las precisas órdenes que dirigirán el arreglo, tranquilidad, substencia y fomento de los indios Guaranís, siguiendo el rumbo de su carácter, antiguo modo de vivir y costumbre". Neste relatório, Riva Herrera atesta sua convicção de que os Guarani não se adaptarão à nova divisão de poderes, tanto pelo fato de que sentem falta de "seus padres" como por que seu tradicional modo de vida prescreve a conjunção dos poderes político e religioso. ${ }^{21}$

Conforme a Instrução, os administradores tinham controle sobre todas as atividades produtivas dos povoados e nenhuma vigilância na prestação de conta aos Superiores. Esta certa "solidão administrativa" proporciounou inúmeras possibilidades (e práticas) de fraudes que acabarão por caracterizar de forma inequívoca o cargo de Administrador. A partir da Instrução, as expressões "codicia y falta de celo" parecerão quase como sinônimo ou adjetivo inseparável do cargo de Administrador.

Em função destas circunstâncias, Bucareli elabora a "Adición a mi Instrucción ${ }^{\prime 22} \mathrm{e}$, principalmente a "Ordenanza de Comércio ${ }^{\prime 23}$ tentando delimitar os poderes dos Administradores, imputando-lhes penalidades sobre o não cumprimento das obrigações previstas e/ou as mancomunações com seus subordinados e superiores. Com a mesma importância que

21 BNRJ. Mss. Vol. I-28-5-40. Ao que tudo indica, este Relatório nāo foi considerado por nenhum dos Superiores de Riva Herrera, pois não há nenhuma referência posterior dele ou de suas informaçōes. Cabe também uma observação sobre a necessidade do Governador Geral em considerar, em 1760, as prescrições do "tradicional modo de vida" do Guarani e, de novo vem a descaracterização de uma vida civilizada, tão insistentemente apontada por Bucareli. Estariam estes indígenas depois de 150 anos convivendo com os princípios do Barroco e da Contra-Reforma, ainda pautando sua conduta pelo "tradicional modo de vida"? Há, pelo menos duas alternativas, ou esse "tradicional" faz parte mais do discurso dos governantes que querem através destes aspectos encontrar a forma e a fórmula mais adequada para encaminhá-los à plena assimilação; ou esse modo tradicional continua a ser válido como pauta de identidade para os indígenas, embora já não tenha como base os mesmos princípios vigentes antes da Conquista.

22 AHNM. Sec. Consejos de Indias, Leg. 21371. "Adición a mi Instrucción de 23 de agosto de 1768, que dejé en los Pueblos del Paraná y Uruguay, y principalmente las Ordenanzas a que debe arreglarse el Comercios de los Frutos, interim S. M. no dispone otra cosa. Buenos Aires, 15 de enero de 1770.

23 AHNM. Sec. Consejos de Indias. Leg. 21371. "Ordenanza para arrgelar el comercio de los españoles con los pueblos de Indios Tapes y Guaranís del Paraná, y Uruguay". Buenos Aires, $1^{2}$ de junio de 1770. 
"regular el comercio de los abundantes frutos" está a preocupação de Bucareli na Adición de 1770 por delimitar as "jurisdicciones de los encargados de la administración", assim como ressaltar uma "cierta dependencia y subordinación en su exercício". O objetivo principal da Adición está em confirmar a nomeação de D. Francisco Bruno de Zavala como único governador para todos Trinta povos, dos quais teria autoridade direta sobre quinze e, contaria com a ajuda de tres Tenentes de Governadores para o restante. Já na Ordenanza, o desempenho das funções de Administrador Geral passa a estar sujeito à intervenção do Protetor de Índios, além da nomeação de Administradores Particulares residentes nas cidades de Assunção, Corrientes e Santa Fé.

Quando apontei que a tônica dos Projetos até 1770, afetava o binômio produção/população dos Povoados, me referia ao fato de que todas as mudanças administrativas visavam uma forma mais efetiva de controlar o aumento da produção e isso, cosignificava uma vigilância contínua sobre a população. Além do mais, a multiplicação*dos cargos administrativos implicava também em salários, definidos pelo Governador de Buenos Aires e suministrados pela produção dos povoados, "como estímulo para que cumpla con las obligaciones de su cargo". Ao Administrador Geral correspondia $8 \%$ do produto líquido dos Trinta Povos, e aos Particulares, o salário de $\$ 300$ Pesos por ano, do fundo comum do povoado por ele administrado. ${ }^{24}$

A partir de 1780 o objetivo dos Projetos se transforma em propostas para conseguir recuperar os povoados da decadência econômica e da deserção da população indígena. A discussão se centra agora nas vantagens e desvantagens do trabalho comunitário e particular visando a não evasão da população e o estímulo para que a produção aumente.

Assim como durante os séculos XVI e XVII as acusações - talvez melhor seria dizer, surpresa - sobre as manifestações da ociosidade e preguiça dos indígenas, estavam intimamente vinculadas a "falta de civilidad y polícia"; agora no século XVIII, se relacionarão também com a defesa da manutenção do sistema de produção comunitário. Com o tempo, o Dorado Sureño se manifestava cada vez mais improdutivo e, logo apareceram opiniōes que vinculavam as dificuldades em conseguir "los progresos de polícia y civilidad" com a manutenção do sistema de comunidade, ganhando cada vez mais espaço as propostas de substituição do sistema misto, somente pela propriedade particular:

24 AHNM. Sec. Consejos de Indias. Leg. 21371. "Ordenanza ... 1770." fol. 18-21; 37-39. 
"dejando alos indios en plena libertad para que cada uno trabaje para su propia utilidad, comercie con sus fructos y efectos de su trabajo e industria, y en todo vivan y sean tratados como los demás vasallos del Rey. ${ }^{25}$

As propostas para remediar a decadência dos povoados aparecerá, conforme as necessidades daqueles que as fazem. O Administrador Geral, Manuel Antonio Pacheco, ao assumir o cargo em 1796 solicita para o bom desempenho de sua função, o controle e subordinação absolutas de seus administrados e "sin dependencia del Superior Gobierno ...(pois) la demasiada dependencia y burocracia administrativa existente, los administradores terminaban por hacer los que querían sin presentar cuentas de nada a nadie". ${ }^{26}$

Já o solitário Governador Intendente do Paraguay, propõe a volta ao sistema jesuítico com a administração deixada para religiosos "cuidadosamente selecionados" e com a continuidade do sistema misto. ${ }^{27} \mathrm{O}$ Governador Intendente resposabilizava a falta de prosperidade da província à "impuesta esclavitud militar" e ao abuso de autoridade dos chefes militares. Lázaro de Ribera estava interessado na formação de um "ejército asalariado", acreditando constituir o principal motivo do abandono e subdesenvolvimento econômico, provocado pelo êxodo e a notável falta de trabalhadorres. Sua avaliação poderia efetivamente estar correta, mas a solução proposta não resolveu o problema da decadência dos povoados.

A princípios do século XIX, o Vice-Rei Marquês de Avilés, pressionado pelas circunstâncias de abandono quase total dos povoados, principalmente pelos homens solteiros - base da mão de obra -, e com a seleção realizada pelo Administrador Geral D. Bruno de Zavala dos "exemplares chefes de família", Avilés decreta a liberação dos trabalhos comunitários das primeiras 323 famílias Guarani. Teoricamente os "liberados" teriam auxílio do fundo comum para a alimentação diária até o

25 CODA. Tomo V: 130-131. "Plan General de gobierno, acomodado a las circunstancias de estos pueblos. (II Parte de la Memoria del Teniente de Gobernador Gonzalo de Doblas, 1785).

26 AHNM. Sec. Consejos de Indias, Leg. 21370. Representaciones de Manuel Antonio Pacheco al Virrey D. Pedro Melo de Portugal. Buenos Aires, 11 de junio y 8 de agosto de 1796.

27 AHNM. Sec. Consejos de Indias, Leg. 21370. Reglamento para el Govierno de los veitisiete pueblos de la Província del Paraguay. Por Lázaro de Ribera, Asunción, 13 de octubre de 1798. 
final do ano seguinte; assim como receberiam da comunidade as ferramentas, bois e animais para começar seus trabalhos, além de terem direito a duas vacas leiteras para cada família, das quais deveriam pagar um peso pelo "empréstimo". ${ }^{28}$

Entretanto, desde o princípio ocorreram problemas para o fiel cumprimento do Deoreto. A liberação recaía sobre o chefe de família extensivo ao grupo doméstico, ou seja, filhos, netos, genros, parentes consaguíneos e afins. Assim, por exemplo o capelão Mathias de Oreda do povoado de Santa Ana, aponta que entre os 9 indicados de seu povoado, foram liberadas 480 almas de ambos sexos. Imediatamente após a concessão da liberdade todos foram embora do povoado. ${ }^{29} \mathrm{Tam}$ bém entre os benefícios recebidos pela comunidade, os liberados tinham direito a um lote de terra, e, no caso dos povoados de Santiago e San Ignácio Guasú e San Carlos não havia terra disponível. ${ }^{30}$

Conforme Susnik o ensaio de liberação terminou rapidamente e foi somente parcial. Os Guarani comunais "reagiram violentamente", contra a obrigação dos trabalhos comunais, provocando a decadência dos povoados missioneiros como causa de uma pobreza ainda maior: a indiferença e libertinagem. ${ }^{31}$ Confesso que busquei compulsivamente esta "violenta reação guarani", e aqui expus suscintamente tudo o que encontrei registrado e, me parece não ser possível afirmar que os Guarani assumiram a referida atitude. É certo que os povoados empobreceram na medida que os Guarani desapareciam deles, mas isso creio, se vincula mais ao fato de que os indígenas já não se sentem obrigados a defender um espaço que não chegaram a assumir como seu, ainda que o defendessem, enquanto lhes servia de resguardo de outras agressões coloniais.

Aos Guarani das Reduções, as propostas liberalizantes se aproximavam a um giro de $180^{\circ}$ que lhes geraram novas preocupações cotidianas. Depois de um século e meio de condicionado isolamento da vida colonial, reproduzindo um sistema de produção e consumo coletivista, sob o atento e paternalista controle dos padres e, com a salvaguarda de

28 AGI. Sec. Buenos Aires, Leg. 322, № 14. Oficio del Virrey al Intendente nombrando los 323 jefes de familia de 27 pueblos que fueron liberados de los trabajos de comunidad, por el Decreto de 27 de enero. Buenos Aires, 18 de feberero de 1800.

29 AGI. Sec. Buenos Aires. Leg. 323. Queja del Capellán Mathias de Oreda ao Virrey Avilés. Santa Ana, 23 de noviembre de 1800.

30 DHA 1914. Tomo III:371. Carta del Frey Vicente Paz ao Marqués de Avilés, San Carlos, 23 de octubre de 1800.

31 Cfe. SUSNIK., Branislava. Una visión socio-antropológica del Paraguay del Siglo XVIII. Museo Antropológico "Andres Barbedo". Asunción. 1990-91:128-129. 
não serem incorporados ao sistema de encomienda; de repente se encontram que, na ordem sócio-econômica, a aborrecida rotina e a inesgotável estabilidade, são invadidas pela concorrência com o vizinho mais próximo, pelo espanhol que passa a viver dentro de seu povoado, e porque paulatinamente tem que pensar no dia seguinte.

A desiguladade da economia dual constituía um fator desagregador: por uma parte, os trabalhos comunais dependiam da capacidade e honestidade do administrador; por outra, a economia livre dos indígenas baseada em seu trabalho particular na chácras particulares, para as quais se permitia dois dias por semana para sua manutenção. Os interesses do governo se concentram no povoado como corpo econômico e não precisamente no povoado como comunidade de índios. As mudanças introduzidas por Bucareli adquirem agora sua verdadeira dimensão. Os indígenas já não sentem o povoado como célula de segurança subsistencial e abandonam sua passividade social expressa na obediência e aparente pleno conformismo. Aos interesses comunitários do povoado opuseram os seus próprios e imediatos. $\mathrm{O}$ descaso dos índios comunais para com as tarefas do povoado e a busca da liberdade através da fuga, encaminhou o processo de liberação legal, ainda que com sérias dificuldades práticas.

Já em 1801 as comunidades Guarani serão afetadas pela guerra entre Espanha e Portugal, na qual mais uma vez os sete povos da banda oriental passam a ser possessão da coroa lusitana. Motivo mais que suficiente para que os ilustrados funcionários elaborem um novo Plano de Governo para os Guarani, partindo dos problemas do governo da província. Nesta ocasião o secretário do Vice-Rei Avilés, D. Miguel de Lastarría, tentou a solução definitiva para as "Muy interesantes colonias orientales del Río de la Plata". ${ }^{32}$

A preocupação inicial dos Projetos de apagar tudo o que existia de "jesuítico", passou a concentrar-se no desenvolvimento da produção e incremento do comércio, e agora corresponde a preocupação com a fronteira. Os Projetos continuam a repetir o mesmo tratamento que acabou por dissipar os primeiros sintomas da doença, convertendo-a em epidemia. Os Projetos para o Governo dos Guarani se esquecem dos próprios e, estes por sua vez, se esquecem do governo.

32 BNM. Sec. Manuscritos. 13264. Também em DHA. (1914). Tomo III:228-229. Reorganización y Plan de Seguridad Exterior de las Muy interesantes Colonias Orientales del Río de la Plata; por Miguel de Lastarría, 1805. 
Através de uma "resistência anárquica", talvez mais individualista e ocasional, os Guarani missioneiros paulatinamente conseguiram sua incorporação econômica na sociedade colonial, através das possibilidades oferecidas por esta: conchavo nas estâncias como peões, serviços prestados nos centros urbanos, ou a deserção pura e simples para o "monte". Nesta integração se contam as possibilidades econômicas que oferece o próprio sistema colonial para os diferentes grupos sociais, e inclusive a disponibilidade destes em aceitá-las. É aqui que a identidade étnica adquire a expressão de condição para a integração. A potencialidade que cada grupo possui para reoriar seus padrões culturais marcarão de forma definitiva o processo que se desenvolve de integração e resistência.

\section{Conclusões Potencialmente Integradoras}

Com a expulsão dos jesuítas e a abertura dos povoados missioneiros à "selvagem vida colonial" os Guarani dos séculos XVI e XVII tiveram a oportunidade de superar o "trauma da conquista" e encaminhar sua inserção na sociedade rioplatina. As Reformas Bourbônicas estudadas através dos Projetos de Governo para as comunidades Guarani, quase poderiam receber o qualificativo de revolução no que respeita a forma como atuaram sobre o potencial de integração Guarani, acomodado com a estabilidade do sistema de reduções e deste dentro do sistema colonial. As barreiras de isolamento são drasticamente rompidas, a segurança susbsistencial entra numa decadência assutadora, desfazendo a idéia do povoado-subsistência e impondo a necessidade da participação direta através do conchavo com menos intermediários possíveis; ou a lenta recuperação de formas alternativas de sobrevivência fora do povoado e dos núcleos urbanos.

As tentativas fracassadas de obrigação da aprendizagem do idioma castelhano, ${ }^{33}$ com a revitalização da máxima colonial dos Habsburgos: "aceptase pero no se cumple", se converterão a médio e longo prazo, em dois comportamentos antagônicos e complementários: enquanto na pro-

33 O próprio Gov. Intendente do Paraguay, se mostra surpreso com a contínua ineficiência do ensino do castelhano e indica os caminhos de instauração do bilingüísmo: "Hemos llegado al extremo de que la lengua del pueblo conquistado sea la que domine". ANA. Sec. Historia, v. 165, n. 1, f. 14. Carta de Lázaro de Ribera al Virrey Melo de Portugal, 1799. 
víncia e no mesmo Paraguai atual, a língua Guarani é desprezada como "lengua de indios sin más", os mesmos indígenas a recuperam e a recriam em sua intensidade simbólica e religiosa, como forma de recuperarem-se a si mesmos.

O desejo de abandonar o povoado e passar a "participar" nas cidades compõe um dos estágios definidos por Glaser $^{34}$ dentro do continuum no qual o indíviduo passa de segregado a marginal até conseguir ser incorporado, e daí ser assimilado pela sociedade envolvente pela que há optado. Esta "opção" implica no processo de mobilidade social que junto com a aculturação - entendida como processo unilateral de recepção de valores -, aos que está disposto a incorporar com o objetivo de não sentir-se marginalizado; formam parte de um mesmo processo de assimilação da sociedade indígena por uma sociedade envolvente. Os "mecanismos de integração" da sociedade colonial se convertem em mecanismos de assimilação a partir da própria transformação do potencial de integração da sociedade indígena que passa a demandar a assimilação numa sociedade que lhe é estranha, tanto quanto não encontra pontos coincidentes com seu próprio grupo.

Nesta medida também se pode entender a deserção como um mecanismo de integração que atua a partir dos indígenas, sem que deixe de ser um mecanismo colonial. Por isso cabe uma advertência sobre a análise do processo de resistência Guarani, pois a deserção pode ser vista simplesmente como "violenta resistência" a "la codicia de los nuevos administradores", mas também como demanda dos próprios Guarani em integrar-se numa sociedade colonial que lhes oferece possibilidades coloniais e marginais, claro está -, de participar da vida regional através do potencial de integração desenvolvido ao longo de todo o contato inter-étnico.

Conseqüentemente, a fuga e a deserção dos povoados cossignificam a demanda por uma integração econômica na sociedade colonial, segundo suas possibilidade de fazer desta participação algo vantajoso: conchavar quando necessitam (ainda que depois o fruto de seu trabalho deva ser compartido com sua comunidade) e/ou escapar para desfrutar o conseguido no trabalho ou das possibilidades que lhe oferecem a vida no "monte". 
Assim, a "política indigenista" da Ilustração nas "Provincias de Abajo" pode não haver conseguido resgatar o esplendor das Missões Jesuíticas, mas ofereceu - evidente que não da forma projetada -, os espaços e as modalidades para o Guarani participar da sociedade global. Tal participação reflete por um lado as dificuldades ideológicas e práticas dos Projetos condicionando o "processo de reguaranização" pelo que passam alguns grupos atuais, nas tentativas de resgate de sua identidade étnica. Uma identidade comprendida através da dinamicidade que adquirem as formas ideológicas das representações coletivas, tal como definiu Bartolomé. ${ }^{35}$ Não se pode afilmar com certeza até que ponto os Guarani perderam a "memória" desta identidade, mas se tentou demonstrar em que medida conservaram e intensificaram simbolicamente os resultados conseguidos desta memória.

35 Cfe. BARTOLOMÉ, Miguel A "Afirmación estatal y negación estatal. (El caso de las minorias nacionales en América Latina)". Suplemento Antropológico, v. XXII, (2:7 13), 1987: 09. 